\title{
Projeto "O Pulo do Gato: a Medicina Veterinária por uma Saúde Única"
}

\section{Cat Jump Project: veterinary medicine for a One Health}

\section{Resumo}

A guarda responsável dos animais de companhia e a educação da sociedade são práticas que visam à promoção do bem-estar animal. Buscando resolver a situação de abandono de felinos existente no Bosque Municipal de Marília, São Paulo, Brasil, foi firmada uma parceria entre a Universidade de Marília (Unimar) e a prefeitura do município para o desenvolvimento do projeto "O Pulo do Gato". Este, executado no período de 2012 a 2014, foi delineado para conscientizar a população quanto aos prejuízos que os animais abandonados poderiam causar no recinto, bem como às implicações da saúde desses gatos que poderiam, inclusive, refletir na saúde humana. Nesse sentido, foi realizado um levantamento em conjunto com o Centro de Educação Ambiental (CEA) localizado no bosque. Um dos aspectos que o projeto executou foi o educacional, atingindo 18.100 crianças do ensino fundamental com visitas in loco e distribuição de material impresso, encenação de teatros, além de oficinas. Outro procedimento adotado foi o manejo populacional dos felinos abandonados com o emprego da castração e doação, que no período envolveu 151 animais, 86 machos (57\%) e 65 fêmeas (43\%), sendo que todos também foram vacinados contra raiva e vermifugados e receberam um microchip de identificação. Pode-se constatar que com essas ações houve uma diminuição considerável do número de felinos abandonados no bosque, bem como o retorno de espécies de animais nativas, principalmente aves que passaram a ser observadas no local com maior frequência. Enfim, o projeto mostrou claramente a importância da medicina veterinária dentro da visão moderna de "saúde única", ou seja, saúde animal, humana e ambiental. 
Guilherme David Galvani

Larissa Berardi Cerqueira Nardi²

Maria Helena Martins ${ }^{3}$

Sônia Cristina Guirado Cardoso ${ }^{4}$

Lupércio Lopers Garrido Neto 5

Melissa Campitelli Ferreira ${ }^{6}$

Fábio Ricardo Barbuglio7

Fábio Fernando Ribeiro Manhoso ${ }^{8}$

Avenida Hygino Muzy Filho, 1001, Campus Universitário

Marília/SP, CEP: 17525-900

\fabiomanhoso@unimar.br

\section{Abstract}

Responsible ownership for pet animals and society education are practices that aim for the promotion of animal welfare. Looking to solve the problem of stray cats population at Marilia/SP Municipal Wood, São Paulo, Brazil, it was settled a partnership between the Marilia University and the town council to develop the project "Cat Jump Project". This one was performed from 2012 to 2014, and included the population awareness towards the damages that the abandoned animals could cause in this place, as well as the implications of these animals health that could also affect human health. Thus, it was performed a survey together with the Environmental Education Center, located in the wood. One of the aspects that the project executed was the community education action, which reached 18,100 children of elementary schools that were attended in spot visits, received a printed material and attended a theater staging and special workshops. Another performed action was the implantation of the stray cats population control with an animal castration-donation program, which in the analyzed period achieved 151 animals, 86 males (57\%) and 65 females ( $43 \%)$, considering that all of them were also vaccinated against rabies, dewormed and received a microchip identification. The obtained results were an important decrease in the number of stray cats found in the wood, and also the return of wild native animal species, especially birds that could be seen more frequently in the wood. This project is one more confirmation that veterinary medicine can play and important role in the "one health" modern view, in other words, animal, human and environment health.

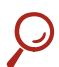

\section{Palavras-chave}

Felinos. Marília. Medicina Veterinária. Guarda responsável. Saúde Única.

\section{Keywords}

Cats. Marília. Veterinary medicine. Responsible ownership. One Health.

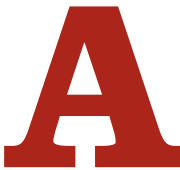

relação entre o ser humano e os animais de companhia tem apresentado grande evolução, tanto que na sociedade moderna eles são, muitas vezes, considerados membros das famílias (SANTANA; OLIVEIRA, 2006). Nesse sentido, os gatos vêm assumindo um papel importante, pois se adaptam facilmente aos apartamentos ou pequenas casas de seus tutores (BEAVER, 2005). No estabelecimento da guarda responsável desses animais, é ao profissional médico-veterinário que cabe a responsabilidade da orientação das condutas destinadas à promoção do seu bem-estar. Contudo, na atualidade, ainda não existe uma legislação dirigida para o controle do comércio e a criação dos gatos e, muitas vezes, a falta de informação pode trazer a insatisfação futura dos tutores, o que culmina com o abandono dos animais e consequentes transtornos na saúde ambiental e/ou das pessoas (SILVANO et al., 2010).

\footnotetext{
1 Médico-veterinário aprimorando em Clínica Médica de Pequenos Animais da Universidade de Marília/SP, Brasil

2 Docente do curso de Medicina Veterinária da Universidade de Marília/SP, Brasil.

3 Presidente da Anima! ONG de proteção animal de Marília/SP, Brasil.

${ }_{4}$ Advogada e secretária municipal do Meio Ambiente de Marília/SP, Brasil.

5 Médico-veterinário da Divisão de Zoonoses do município de Marília/SP, Brasil.

6 Médica-veterinária responsável técnica pelo Bosque Municipal de Marília/SP, Brasil.

7 Médico-veterinário coordenador técnico da Vetnil.

8 Docente do curso de Medicina Veterinária da Universidade de Marília/SP, Brasil.
} 
Os felinos são predadores oportunistas e extremamente adaptáveis e, graças ao seu instinto de caça, têm acesso a fontes alimentares diversificadas, incluindo na sua dieta presas bem distintas como aves, roedores e insetos, o que em alguns momentos pode representar uma ameaça ambiental, causando prejuízos à biodiversidade, aos ecossistemas naturais e à economia, além de sérios riscos à saúde humana (DAUPHINÉ; COOPER, 2009; FERREIRA et al., 2011; ZWARG et al., 2013). Kays e DeWan (2004) afirmam que, devido ao fato de os felinos domésticos serem bem alimentados como animais de estimação, sua caça aparenta ser mais recreativa ou oportunista, porém chamam atenção por conta de as aves serem o grupo de animais mais afetado pela sua predação. Nesse sentido, e com o intuito de demonstrar os possíveis impactos ambientais que os gatos podem causar, Van Heezik et al. (2010) observaram no período de um ano, em Dunedin, na Nova Zelândia, o comportamento de 151 gatos e o que eram as suas presas preferenciais, detectando a captura de 1887 presas, incluindo: aves (37\%), roedores (34,3\%) e invertebrados (19,3\%).

No Brasil, Pereira (2009) realizou um estudo na Ilha do Mel/PR com 36 felinos errantes e domésticos em duas diferentes áreas definidas para análise, ambas limítrofes à área de preservação ambiental de interesse e com influência antrópica. Os felinos, inclusive os domésticos, foram observados caçando e foi levantada a hipótese de que eles estivessem impactando as populações de suas presas na área de estudo, necessitando de atenção quanto à elaboração de planos de manejo da espécie. Rangel e Neiva (2013), na cidade de São Paulo/SP, catalogaram os casos de predação da avifauna por cães e gatos domésticos atendidos em estabelecimento veterinário no período de 1993 a 2011 e os gatos foram os responsáveis por $77,6 \%$ do total de ataques.

Da legislação brasileira que regulamenta a causa animal, a Lei dos Crimes Ambientais, Lei no 9.605/1998, estabelece em seu artigo 32 que o responsável pela "prática de atos de abuso, maus tratos, ferir ou mutilar animais silvestres, domésticos ou domesticados, nativos ou exóticos" é passível de detenção por três meses a um ano, além de multa (BRASIL, 1998). Ainda no prisma legal, visto que os municípios têm de organizar as suas ações locais, muitos possuem uma legislação própria, como é o caso de Marília/ SP, no qual, de um arsenal de mais de 30 leis que envolvem a causa animal, ressalta-se a de $n^{\circ} 7.324 / 2011$, que instituiu, de forma efetiva e abrangente, o Programa de Controle de Natalidade de Animais Domésticos, visando à manutenção de boas condições de saúde, bem-estar animal e prevenção de zoonoses, com o emprego de ações educativas sobre propriedade e posse responsável dos animais domésticos, incluindo artigos que regulamentam a esterilização cirúrgica para cães e gatos, bem como que a realização de tal procedimento é restrita aos médicos veterinários, devendo ser executadas apenas em clínicas, hospitais ou instalações públicas apropriadas mediante a cobrança de preços acessíveis para a população (MARÍLIA, 2011).

Natoli et al. (2006), analisando as colônias de felinos distribuídas em Roma, Itália, no período de 1991 a 2000, avaliaram a quantidade de felinos e aplicaram um programa de captura, com posterior castração e reintrodução dos animais ao seu habitat. Constataram que inicialmente havia 103 colônias com um número variável de 5 a 50 animais por colônia. Após a execução do projeto, foi detectado que em 55 colônias houve a diminuição do número de animais, em 28 ele se manteve estável e em 20 houve aumento, uma das colônias foi totalmente extinta e na outra havia apenas um animal. Portanto, o número de animais passou a ser de 1 a 40 animais. No transcurso do projeto, cerca de 8.000 felinos foram castrados, porém o número de imigração e abandono de gatos continuou a crescer, destacando a dificuldade existente para o controle dos animais errantes. No entanto, concluíram que a castração contribuiu para o controle da população local de felinos.

Finkler e Terkel (2012), em Tel Aviv, Israel, aplicaram um questionário junto com clínicas veterinárias de toda a cidade, buscando o conhecimento dos fatores que contribuíam para a superpopulação de gatos errantes locais. As conclusões obtidas revelaram que $61,4 \%$ dos tutores preferiam adotar felinos castrados, porém $38,6 \%$ tinham dúvidas quanto à contribuição da castração, pois acreditavam que a experiência da maternidade seria importante para o animal; também houve questionamentos quanto ao custo do procedimento e alguns, inclusive, julgaram que o procedimento era um ato imoral. Para 24,3\% dos entrevistados, a causa mais comum para o abandono dos felinos era o comportamento dos animais. Ao indicarem a caracterização dos entrevistados, viram que as mulheres, jovens, mais instruídas e pertencentes a uma classe de maior renda eram as mais preocupadas com o controle de natalidade dos animais.

Na cidade de Seropédica/RJ, Joffily et al. (2013) aplicaram um questionário para levantar os cuidados gerais que os proprietários tinham com os seus animais e sobre a importância que eles atribuíam para a contribuição da castração na saúde pública. A conclusão obtida foi que havia a necessidade de um maior debate, pois muitos foram contrários a práticas da castração e que, inclusive, permitiam o livre trânsito de seus animais, o que poderia resultar em um grande número de cópulas e, consequentemente, ninhadas não planejadas.

Fernandes et al. (2014), em Marília, relataram os registros do programa de castração efetuado no município, no período de 2008 a 2011, que incluem um total de 968 animais castrados, 489 cães e 479 gatos. Destacaram também que, no decorrer desses anos, foram realizadas 
campanhas de educação quanto à guarda responsável com escolas de ensino fundamental, o que redundou em um aumento progressivo na adesão dos proprietários quanto às campanhas de castração dos seus animais.

Um aspecto a ser destacado quanto à ocorrência de felinos errantes é justamente o seu potencial zoonótico. Serra, Uchôa e Coimbra (2003) encontraram 63,4\% de resultados positivos no exame coproparasitológico de amostras de fezes de 131 gatos errantes e domiciliados nas cidades de Niterói/RJ e Rio de Janeiro/RJ, com predominância para Ancylostoma sp (43,5\%), Toxocara sp (19,1\%) e Cystoisospora sp (43,5\%). As amostras positivas para gatos domiciliados foram de $38,5 \%$ e para errantes de $87,9 \%$.

No cenário da raiva transmitida por morcegos, os gatos têm sido animais negligenciados quanto ao seu papel na epidemiologia da raiva, pois eles têm o hábito de caçar os quirópteros. De fato, no estado de São Paulo foram registrados casos de raiva humana transmitidos por gatos em que a variante de vírus isolada foi a três, que é mantida pelo morcego hematófago (MORAES et al., 2011).

Galvani et al. (2014) investigaram a ocorrência de anticorpos antitoxoplasma em felinos abandonados no Bosque Municipal Rangel Pietraroia da cidade de Marília/SP e constataram que, de 50 animais submetidos ao exame sorológico de imunofluorescência indireta, 13 (26\%) foram classificados como reatores positivos, o que evidencia uma situação de risco para os frequentadores do bosque, principalmente para as crianças que utilizam o banco de areia para diversão.

Com o exposto, denota-se que o recinto a ser estudado encontra-se atualmente com um número estimado em 300 felinos errantes, representando risco à fauna natural do habitat, principalmente aves, além da saúde das pessoas que se utilizam do local para seus momentos de lazer, caracterizadas principalmente por crianças e idosos.

\section{Material e método}

Com o intuito de diminuir o abandono de felinos, junto com Bosque Municipal Rangel Pietraroia de Marília/ SP foi instituído o projeto "O Pulo do Gato", idealizado em parceria público-privada, envolvendo a Secretaria Municipal do Meio Ambiente, Secretaria Municipal da Saúde, Universidade de Marília, por meio de seu curso de medicina veterinária, Anima! ONG de Proteção Animal e Vetnil Produtos Veterinários. O projeto iniciou os trabalhos em junho de 2012 e várias ações foram desenvolvidas nas frentes: educacional, com os alunos da rede municipal de ensino fundamental em visitas in loco no bosque, onde vivenciaram a rotina local e os cuidados destinados aos animais do recinto; bem como a realização de palestras, teatros e oficinas nas escolas com a distribuição de folhetos, cartilhas e apostilas paradidáticas; distribuição do mesmo material à população visitante e participante das atividades no bosque; divulgação pela imprensa local; manejo populacional de felinos com a castração, utilizando-se do protocolo anestésico inalatório e seguindo-se à técnica da orquiectomia nos machos e ovariosalpingohisterectomia nas fêmeas, juntamente com a vacinação antirrábica e a vermifugação à base de febendazol, pamoato de pirantel e praziquantel, além da microchipagem realizadas junto com o Hospital Veterinário da Universidade de Marília com apoio da Vetnil; doação responsável dos animais pela Anima! ONG de Proteção Animal, contemplando inclusive termo de compromisso.

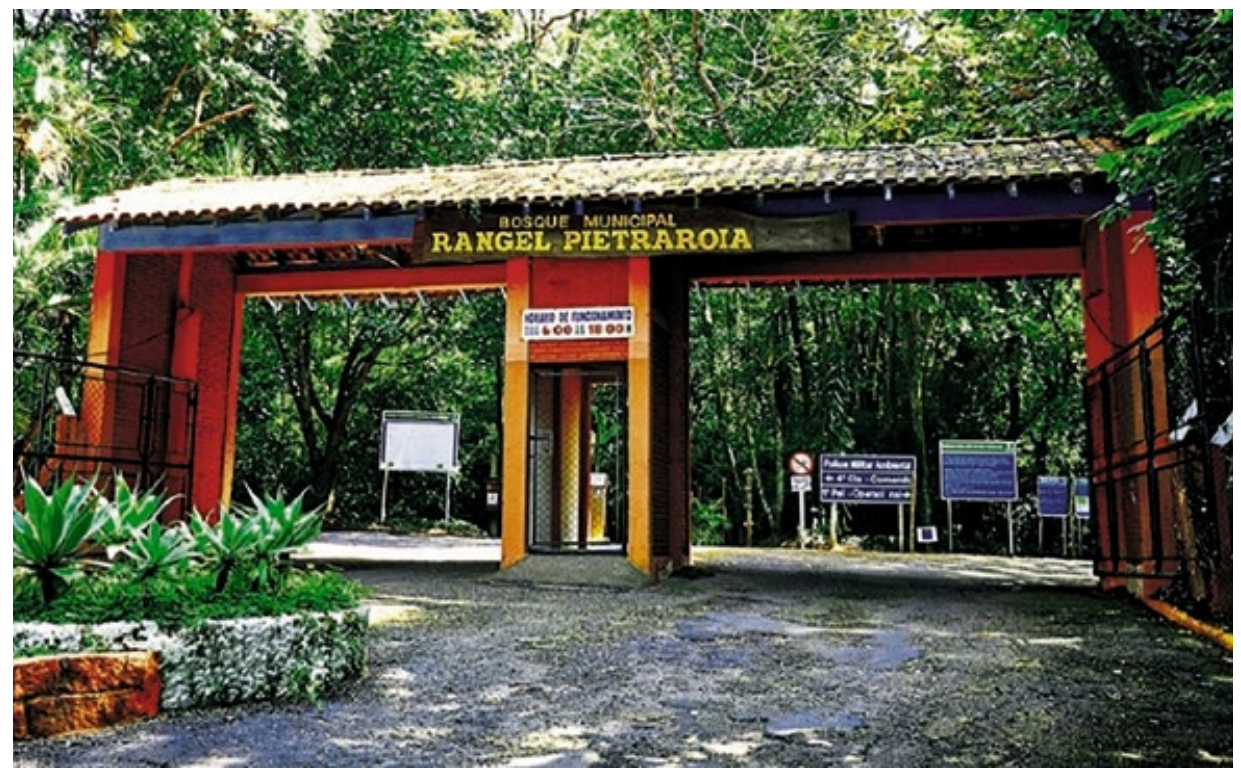

Figura 1 - Portal do Bosque Municipal Rangel Pietraróia Marília/SP. 


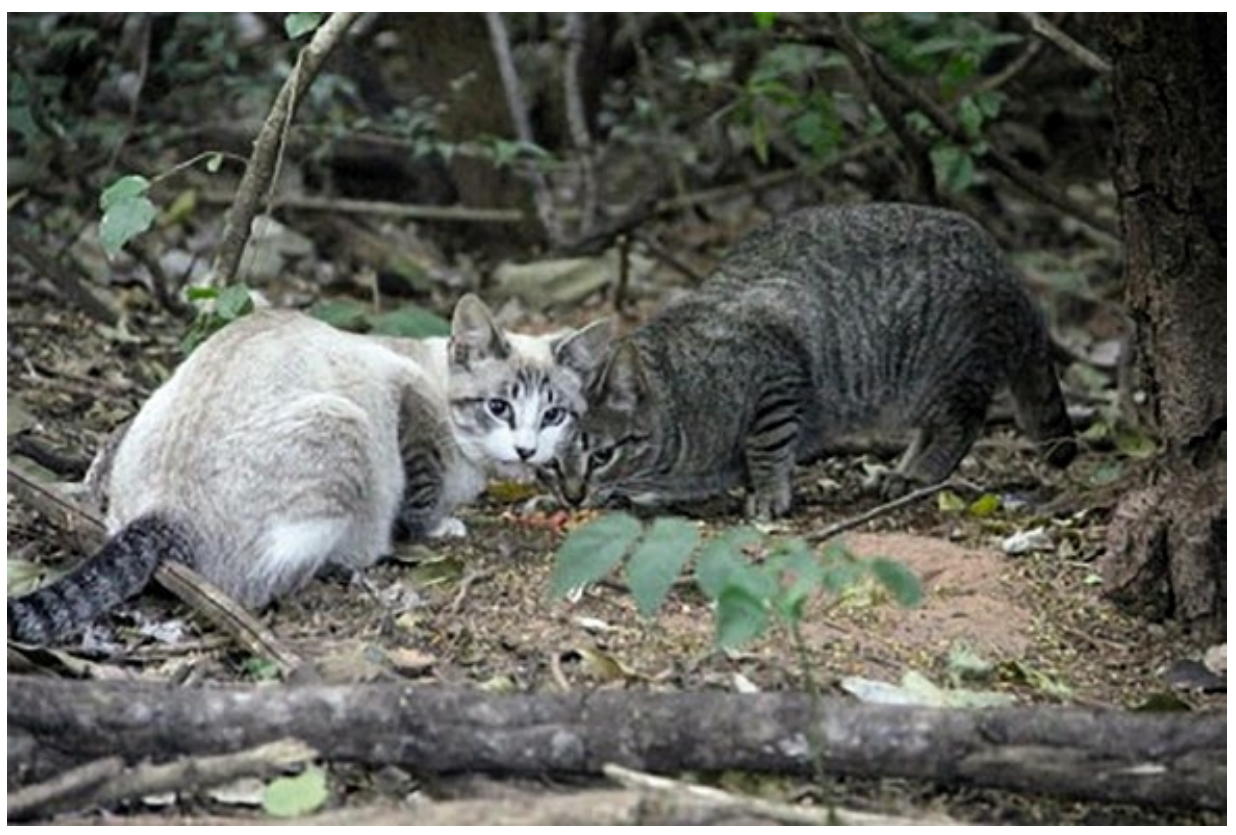

Figura 2 - Felinos abandonados no Bosque Municipal Rangel Pietraróia Marília/SP.
Com a implantação do projeto, investiu-se de forma maciça nas mídias sociais, bem como na imprensa local com o intuito da plena divulgação. O projeto foi levado até a rede de ensino municipal em 43 escolas do ensino infantil e fundamental, atingindo aproximadamente $61 \%$ de todos os estudantes matriculados, ou seja, 18.100, que tiveram contato com o assunto por meio de apostilas, palestras, teatros, visitas e oficinas. Foram desenvolvidas ações relacionadas ao projeto com a intenção de atingir o maior número de alunos da rede municipal para a conscientização dessas crianças, enfocando a posse responsável dos felinos e seu impacto na questão ambiental e de saúde pública, com cartilhas intituladas de "Quero colo" e "Criança responsável faz a sua parte", considerando serem essas crianças as melhores multiplicadoras do assunto. Outra ação desenvolvida para a conscientização da população foi a distribuição do mesmo material aos visitantes do bosque, bem como a fixação de cartazes em estabelecimentos comerciais do município. No mesmo ano em que o projeto foi iniciado, ele foi apresentado no X Simpósio de Diálogo Interbacias de Educação Ambiental em Recursos Hídricos, realizado na cidade de São Pedro/SP.

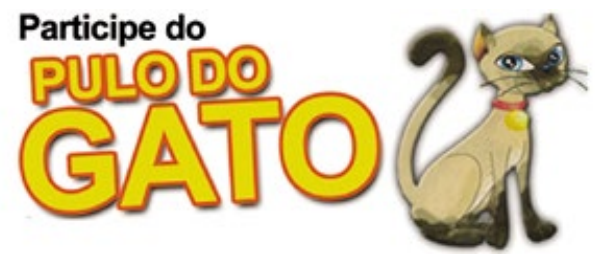

Figura 3 - Logo do Projeto.

\section{Resultado e discussão}

No período considerado, 2012 a 2014, foram castrados, vacinados, vermifugados e microchipados um total de 151 felinos, 65 fêmeas (43\%) e 86 machos (57\%), com idade estimada situada entre cinco meses a oito anos, mas com predominância de filhotes, sendo que todos esses animais foram devidamente adotados de forma responsável. A estimativa do número de felinos abandonados no local no transcurso do período estudado diminuiu consideravelmente. Em entrevistas com os responsáveis que trabalhavam diretamente no bosque, foi relatado que eles haviam observado que havia ocorrido uma diminuição substancial da prática de abandono de felinos no bosque e também o retorno de algumas espécies de vida livre, principalmente aves, que estavam sendo dizimadas pela ação predatória dos felinos abandonados.

Como observado, o abandono de felinos em qualquer circunstância pode causar impactos à Saúde Única. Autores deixam claro que, pelo seu instinto de caça, o felino pode degradar o meio ambiente, representando risco aos animais que vivem no habitat natural, como ocorreu no bosque de Marília. A aplicação do projeto teve como uma das consequências positivas a constatação, por parte dos trabalhadores locais, do retorno das espécies de vida livre, o que corrobora as informações de Pereira (2009), preocupado com a ação predadora de felinos errantes na Ilha do Mel/PR, e de Rangel e Neiva (2013), que confirmaram que os ataques a animais de fauna livre foram oriundos principalmente dos felinos errantes em São Paulo/SP. Pode-se relacionar ainda com os achados de Van Heezik et al. (2010), que constataram serem as 
aves, roedores e invertebrados os mais agredidos por felinos errantes, respectivamente, bem como com Zwarg et al. (2013), que demonstraram o impacto na fauna, principalmente nas aves.

No que tange ao risco para a saúde pública de abandono de felinos, esta se caracteriza como uma das principais preocupações dos autores, bem como figura como foco central desse projeto. Essa preocupação no abandono de felinos em recinto com as características do bosque municipal é compreensível visto o público que o utiliza para seus dias de lazer, representado principalmente por crianças. Sendo assim, confirmam essa preocupação Serra, Uchôa e Coimbra (2003), ao mostrarem que os animais errantes podem ser potenciais transmissores de doenças por meio da contaminação ambiental pelas fezes, seguido por Moraes et al. (2011), que alertaram que os felinos não podem ser negligenciados na transmissão da raiva, e Galvani et al. (2014), que utilizando do mesmo local e material principal, os felinos abandonados no bosque municipal de Marília, observaram a ocorrência do Toxoplasma gondii em $26 \%$ das amostras avaliadas. De todas as ações, a de retirar os animais abandonados no bosque é a de fundamental importância para a Saúde Única, porém deve ser feita respeitando os critérios de bem-estar animal, o qual foi seguido proporcionando doação responsável a esses animais, após castrados e submetidos à vermifugação, vacinação e identificação. $\mathrm{O}$ fato de retirar os animais abandonados concorda com os achados de Natoli et al. (2006), que conseguiram reduzir a quantidade de colônias e animais por colônias, mas os resultados obtidos no projeto "O Pulo do Gato" são muito mais expressivos, pois a somatória de ações representou a diferença, não ficando somente na castração dos animais.

Por fim, constata-se a importância da integração visando um bem comum, por meio da parceria público-privada, tendo na medicina veterinária o alicerce para a construção desse projeto que, com certeza, fez que a sociedade interagisse nas responsabilidades geradas visando proteger o todo, ou seja, os animais, o ambiente e a saúde daqueles que se utilizaram e utilizarão o parque.

\section{Considerações finais}

Pode-se aferir no projeto que, com a união de forças e um planejamento estratégico, os objetivos foram muito mais facilmente atingidos, conseguindo-se realizar um trabalho com fundo educacional que contemplou toda a sociedade do município estudado, da criança ao adulto, pelos mais variados meios. A captura e retirada dos felinos abandonados no bosque, devidamente castrados e postos para doação, representou uma preocupação com a saúde e o bem-estar dos animais, pois foram doados seguindo essas necessidades. Portanto, o projeto atingiu seus objetivos, pois houve uma redução substancial do abandono de animais num período de dois anos de sua implantação, índice atingido pelo trabalho em conjunto dos envolvidos

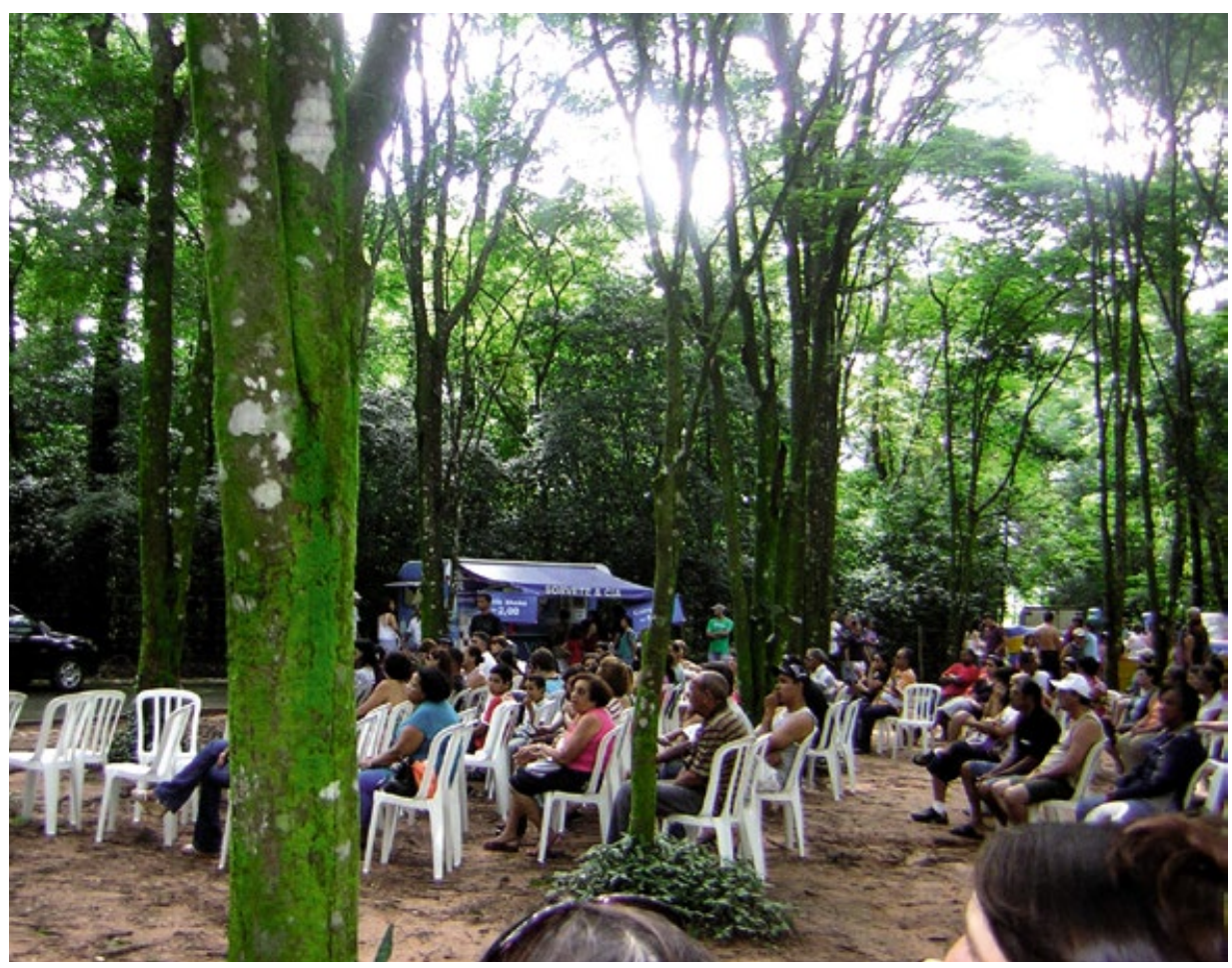

Figura 4 - Apresentação do Projeto aos visitantes do Bosque Municipal Rangel Pietraróia Marília/SP. 
e pela aceitação da comunidade na preservação geral do habitat cientes também do reflexo que todas essas medidas gerariam na saúde pública. Sendo assim, acredita-se que o projeto conseguiu demandar perfeitamente o que representa o médico-veterinário na Saúde Única, a qual, com o controle dos felinos, possibilitou a saúde dos animais, ambiental e, principalmente, das pessoas. (-)

\section{Referências}

BEAVER, B. V. Comportamento felino: um guia para veterinários. 2. ed. São Paulo: Roca, 2005. p. 1-47.

BRASIL. Lei n 9.605, de 12 de fevereiro de 1998. Dispõe sobre as sanções penais e administrativas derivadas de condutas e atividades lesivas ao meio ambiente, e dá outras providências. Diário Oficial da União, Poder Legislativo, Brasília, DF, 13 fev. 1998, Seção 1, p. 1. Disponível em: <https://goo.gl/uj5XEF>. Acesso em: 11 mar. 2016.

DAUPHINÉ, N.; COOPER, R. J. Impacts of free-ranging domestic cats (Felis catus) on birds in the United States: a review of recent research with conservation and management recommendations. In: INTERNATIONAL PARTNERS IN FLIGHT CONFERENCE, 4., 2008, McAllen. Anais... McAllen: Partners in Flight, 2009. p. 205-219.

FERNANDES, T. R. et al. Ações públicas no controle populacional e posse responsável de cães e gatos aplicadas no município de Marília/SP no período de 2008 a 2011. Unimar Ciências, Marília, v. 23, n. 1-2, p. 23-28, 2014.

FERREIRA, J. P. et al. Human-related factors regulate the spatial ecology of domestic cats in sensitive areas for conservation. PLoS One, San Francisco, v. 6, n. 10, 2011. Disponível em: <https:// goo.gl/axVGAz>. Acesso em: 27 nov. 2015.

FINKLER, H.; TERKEL, J. The contribution of cat owners' attitudes and behaviours to the free-roaming cat overpopulation in Tel Aviv, Israel. Preventive Veterinary Medicine, Amsterdam, v. 104, n. 1-2, p. 125-135, 2012.

GALVANI, G. D. et al. Ocorrência de anticorpos anti-Toxoplasma gondii em Felis domesticus errantes em bosque municipal da cidade de Marília, São Paulo, Brasil. Revista de Educação Continuada em Medicina Veterinária e Zootecnia do CRMV-SP, São Paulo, v. 12, n. 2, p. 28-33, 2014.

JOFFILY, D. et al. Medidas para o controle de animais errantes desenvolvidas pelo grupo Pet Medicina Veterinária da Universidade Federal Rural do Rio de Janeiro. Em extensão, Uberlândia, v. 12, n. 1, p. 197-211, 2013.
KAYS, R. W.; DEWAN, A. A. Ecological impact of inside/ outside house cats around a suburban nature preserve. Animal Conservation, Cambridge, v. 7, n. 3, p. 273-283, 2004.

MARÍLIA (Cidade). Secretaria Municipal da Administração. Lei $\mathrm{n}^{\circ} 7324$, de 11 de outubro de 2011. Modifica a Lei $\mathrm{n}^{\circ} 6700$, de 20 de dezembro de 2007, que institui o programa de Controle de Natalidade de Animais Domésticos no município de Marília. Marília, 11 out. 2011. Disponível em: <https://goo.gl/JvVMAe>. Acesso em: 27 nov. 2015.

MORAES, J. E. C. et al. Raiva felina no município de Jaguariúna, estado de São Paulo, em 2010. BEPA, São Paulo, v. 8, n. 96, p. 4-10, 2011.

NATOLI, E. et al. Management of feral domestic cats in the urban environment of Rome (Italy). Preventive Veterinary Medicine, Amsterdam, v. 77, n. 3-4, p. 180-185, 2006.

PEREIRA, D. L. P. Avaliação da presença de gatos (Felis catus L.) em áreas de entorno de unidade de conservação, na Ilha do Mel, Paranaguá, litoral do estado do Paraná. 2009. 51 f. Trabalho de Conclusão de Curso (Especialização em Gestão de Recursos Naturais) - Pontifícia Universidade Católica do Paraná, Curitiba, 2009.

RANGEL, C. H.; NEIVA, C. H. M. B. Predação de vertebrados por cães Canis lupus familiaris (Mammalia: Carnivora) no Jardim Botânico do Rio de Janeiro, RJ, Brasil. Biodiversidade Brasileira, Brasília, DF, v. 3, n. 2, p. 261-269, 2013.

SANTANA, L. R.; OLIVEIRA, T. P. Guarda responsável e dignidade dos animais. Revista Brasileira de Direito Animal, Salvador, v. 1, n. 1, p. 67-104, 2006.

SERRA, C. M. B.; UCHÔA, C. M. A.; COIMBRA, R. A. Exame parasitológico de fezes de gatos (Felis catus domesticus) domiciliados e errantes da Região Metropolitana do Rio de Janeiro, Brasil. Revista da Sociedade Brasileira de Medicina Tropical, Uberaba, v. 36, n. 3, p. 331-334, 2003.

SILVANO, D. et al. Divulgação dos princípios da guarda responsável: uma vertente possível no trabalho de pesquisa a campo. Revista Eletrônica Novo Enfoque, Rio de Janeiro, v. 9, n. 9, p. 64-86, 2010. Disponível em: <https://goo.gl/XJSYHm>. Acesso em: 27 nov. 2015.

VAN HEEZIK, Y. et al. Do domestic cats impose an unsustainable harvest on urban bird populations? Biological Conservation, Barking, v. 143, n. 1, p. 121-130, 2010.

ZWARG, T. et al. Predação da avifauna nativa por cães e gatos na cidade de São Paulo, Brasil: estudo retrospectivo (1993-2011). Clínica Veterinária, São Paulo, v. 18, n. 106, p. 106-113, 2013. 